The Cryosphere Discuss., 5, 1239-1262, 2011

www.the-cryosphere-discuss.net/5/1239/2011/

doi:10.5194/tcd-5-1239-2011

(c) Author(s) 2011. CC Attribution 3.0 License.

\title{
Application of asymptotic radiative transfer theory for the retrievals of snow parameters using reflection and transmission observations
}

H. S. Negi ${ }^{1}$, A. Kokhanovsky ${ }^{2}$, and D. K. Perovich ${ }^{3}$

${ }^{1}$ Snow and Avalanche Study Establishment, Him Parisar, Sector-37A, Chandigarh 160036, India

${ }^{2}$ Institute of Environmental Physics, University of Bremen, O. Hahn Allee 1, 28359 Bremen, Germany

${ }^{3}$ US Army Cold Region Research and Engineering Laboratory, Hanover, New Hampshire 03755-1290, USA

Received: 2 March 2011 - Accepted: 12 April 2011 - Published: 21 April 2011

Correspondence to: H. S. Negi (hs.negi@sase.drdo.in)

Published by Copernicus Publications on behalf of the European Geosciences Union.

Application of asymptotic radiative transfer theory

H. S. Negi et al.
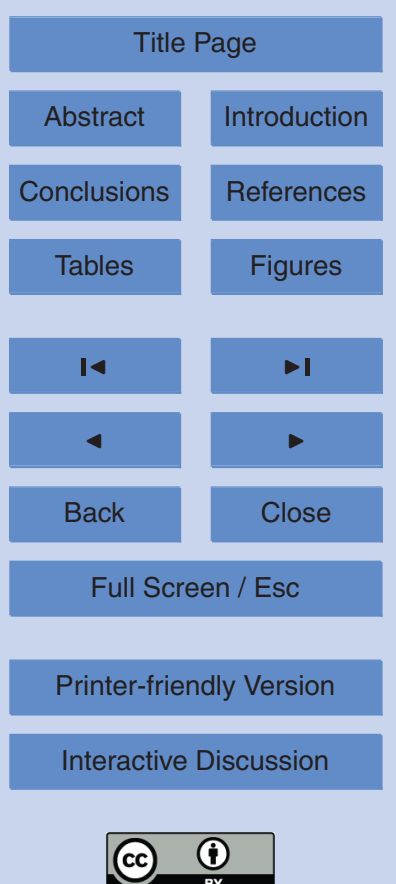


\section{Abstract}

An asymptotic analytical radiative transfer (AART) theory was used to retrieve snow optical parameters such as extinction coefficient, diffuse exponent, asymptotic flux extinction coefficient (AFEC), snow optical thickness and probability of photon absorp5 tion (PPA). This theory was applied to the reflection and transmission data for a temperate snow cover from 400-1000 nm wavelength region, to retrieve AFEC for different types of snow cover (thick, thin, dry, wet, new and old snow). The AFEC values were found at $450 \mathrm{~nm}$ wavelength region in the range from 0.06 to $0.22 \mathrm{~cm}^{-1}$, where high values were observed for increased wetness and impurity in snow. A good agreement between AART retrieved and other radiative transfer model retrieved parameter shows that AART theory can work well for different types of snow. The extinction coefficients for temperate snow ranged from 0.5 to $1.0 \mathrm{~mm}^{-1}$ and the e-folding depths ranged from 5 to $25 \mathrm{~cm}$. The snow physical characteristics such as grain size and density were also retrieved using derived optical parameters and found in agreement with ground

15 measurements. The main advantages of the proposed AART method are the simple analytical equations that provide a valuable alternative from complex numerical radiative transfer solutions.

\section{Introduction}

The interaction of solar radiation with a snow cover has many applications in the study of the Earth's radiation balance, remote sensing, snow metamorphism, snow photochemistry and snow ecosystem. The snowpack can be treated as a turbid medium having ice grains of different shape and sizes with air in the pores. The interaction of solar radiation with such a turbid medium can be described by radiative transfer theory. The solutions of the integro-differential radiative transfer equation (RTE) are used to study media having different internal microstructure (Kokhanovsky, 2006). A number of numerical and analytical techniques has been developed to date (Chandrasekhar,

\section{Application of asymptotic radiative transfer theory}

H. S. Negi et al.

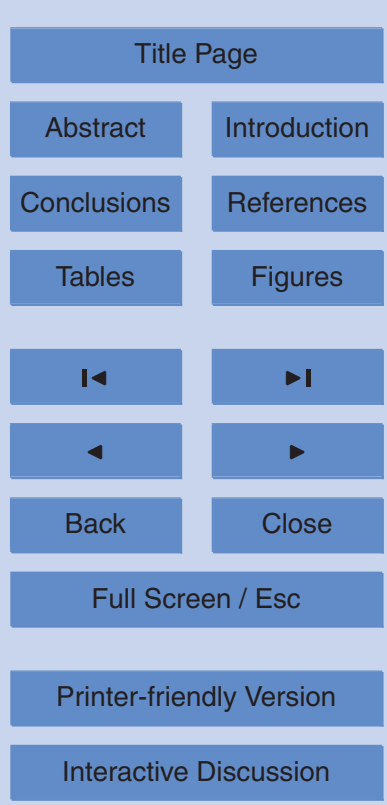


1950; Dunkle and Bevans, 1956; Sobolev, 1975; Van de Hulst, 1980; Nakajima and Tanaka, 1988; Thomas and Stamnes, 1999; Siewert, 2000; Liou, 2002; Mishchenko, 2002). The popular numerical algorithm technique uses an iterative approach to obtain the solution for single scattering. The obtained solution is substituted in the integral 5 term of RTE to find the next iteration and the procedure is repeated until convergence is reached. However, the iteration technique requires quite large computational time for optically thick media. Therefore, another approach has been developed to treat the special case of an optically thick turbid medium. In particular, this technique allows us to represent the turbid layer reflectance as a combination of the reflectance for the 10 case of a semi-infinite turbid medium minus a correction term, which accounts for the finite thickness of a layer under consideration. The corresponding asymptotic analytical radiative transfer theory has been studied by Rozenberg (1967), Sobolev (1975), Minin (1988), Zege et al. (1991), Yanovitskij (1997), and Kokhanovsky (2006).

Reflection and transmission are important properties of a turbid medium that are 15 needed to determine the inherent optical parameters of the medium. The extinction coefficient, single scattering albedo and phase functions are the important fundamental optical parameters in radiative transfer theory needed to retrieve physical parameters of a turbid medium. Many of studies reported on light reflection or albedo from a snow cover but very few studies have examined light transmission through a snow$20 \quad \mathrm{pa}$ Perovich (2007) studied light reflection and transmission by a temperate snow cover and estimated the snow extinction coefficient. In his study two detectors were used to measure reflected and transmitted irradiance.

In the present study an attempt has been made to study snow as weakly absorbing optically thick medium using reflection and transmission functions. Different analytical equations of AART theory were described to retrieve the important snow optical characteristics such as extinction coefficient, optical thickness, diffuse exponent, asymptotic flux extinction coefficient, e-folding depth and probability of photon absorption. These equations were used to analyze the reflected and transmitted data collected

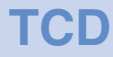

$5,1239-1262,2011$

\section{Application of asymptotic radiative transfer theory}

H. S. Negi et al.

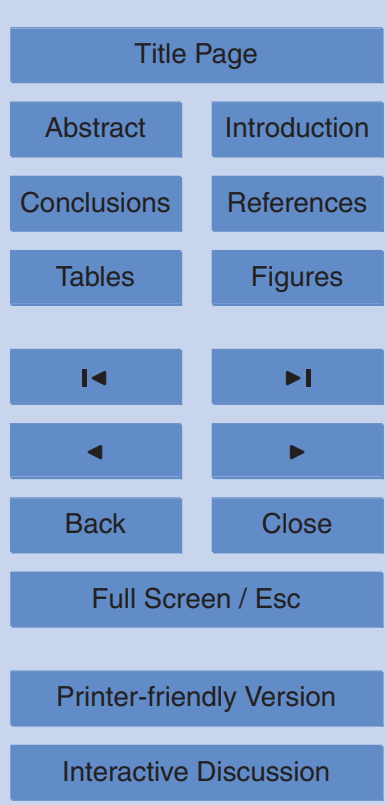


by Perovich (2007) from a temperate snow cover for different types of snow. The results obtained for AFEC using AART theory were compared with previously retrieved AFEC by Perovich (2007) using two-stream radiative transfer theory from Dunkle and Bevans (1956). The retrieved optical properties were also used to retrieve snow phys5 ical properties such as effective grain size and snow density to compare with ground observations.

\section{Theory}

For an optically thick $\left(\tau_{0} \rightarrow \infty\right)$ finite turbid layer (valid for $\left.\omega_{0} \rightarrow 1\right)$, the asymptotic relations for reflection and transmission functions can be presented as (Sobolev, 1975;

10 Zege et al., 1991; Kokhanovsky, 2006);

$R\left(\tau_{0}, \mu, \mu_{0}, \varphi\right)=R_{\infty}\left(\mu, \mu_{o}, \varphi\right)-T\left(\tau_{0}, \mu, \mu_{o}\right) m \exp \left(-k \tau_{0}\right)$,

and

$T\left(\tau_{0}, \mu, \mu_{o}\right)=t K_{0}(\mu) K_{0}\left(\mu_{0}\right)$.

Where $R_{\infty}\left(\mu, \mu_{o}, \varphi\right)$ is the reflection function of a semi-infinite medium with the local

optical characteristics $\left(\omega_{0}, p(\theta)\right), m=e^{-y}, k$ is the diffuse exponent, $t$ is global transmittance and $\tau_{0}$ is optical thickness of the medium. Here $\omega_{0}$ is single scattering albedo, $p(\theta)$ is phase function and $y$ is defined by $y=4 \sqrt{\frac{1-\omega_{0}}{3(1-g)}}$, where $g$ is asymmetry parameter. $\mu_{0}=\cos \vartheta_{0} ; \mu=\cos \vartheta ; \vartheta_{0}, \vartheta$ and $\varphi$ are solar zenith, viewing zenith and relative azimuth angle, respectively. Function $K_{0}\left(\mu_{0}\right)$ is called the escape function and can be given approximately by (Kokhanovsky, 2003):

$K_{0}\left(\mu_{0}\right)=\frac{3}{7}\left(1+2 \mu_{0}\right)$.

Equations (1) and (2) can be used for an analytical solution of the inverse problem and the determination of snow optical characteristics. This can be done using spherical

Application of asymptotic radiative transfer theory

H. S. Negi et al.

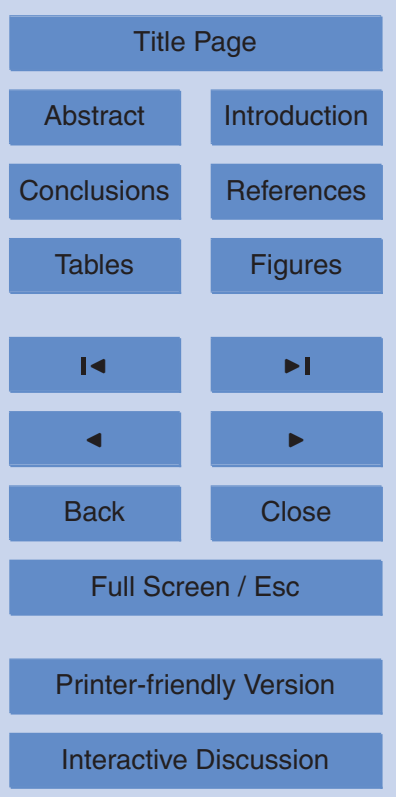


albedo and global transmittance measurements. In case of weakly absorbing optically thick media; the spherical albedo $(r)$ and global transmittance $(t)$ can be derived in the following form (Rozenberg 1967; Kokhanovsky, 2006);

$r=\frac{\sinh (x)}{\sinh (x+y)}$,

5 and

$t=\frac{\sinh (y)}{\sinh (x+y)}$,

where $x=k \tau, y=4 k q$, and $q=1 /(3(1-g))$ (Zege et al., 1991).

The diffuse exponent $(k)$ depends on the single scattering $\left(\omega_{0}\right)$ and asymmetry parameter $(g)$, as explained by Zege et al., 1991 by the following relation:

$10 k=\sqrt{3\left(1-\omega_{0}\right)\left(1-\omega_{0} g\right)}$.

Similarly the snow optical characteristics can also be defined using the reflectance and transmittance functions. It follows for the reflection function of a semi-infinite medium $R_{\infty}\left(\mu, \mu_{o}, \varphi\right)$ (Zege el al., 1991):

$R_{\infty}\left(\mu, \mu_{0}, \varphi\right)=R_{\infty}^{0}\left(\mu, \mu_{o}, \varphi\right) \exp \left(-y D\left(\mu, \mu_{0}, \varphi\right)\right)$,

$R\left(\tau_{0}, \mu, \mu_{o}, \varphi\right)=R_{\infty}^{0}\left(\mu, \mu_{o}, \varphi\right) \exp \left(-y D\left(\mu, \mu_{0}, \varphi\right)\right)-T\left(\mu, \mu_{o}\right) \exp (-y-x)$,

with

${ }_{20} T\left(\mu, \mu_{o}\right)=\frac{\sinh (y)}{\sinh (x+y)} K_{0}(\mu) K_{0}\left(\mu_{0}\right)$.

Equations (7) to (9) can be solved to retrieve $x$ and $y$ parameters, which can be further used to retrieve different snow parameters by analytical equations.

Application of asymptotic radiative transfer theory

H. S. Negi et al.

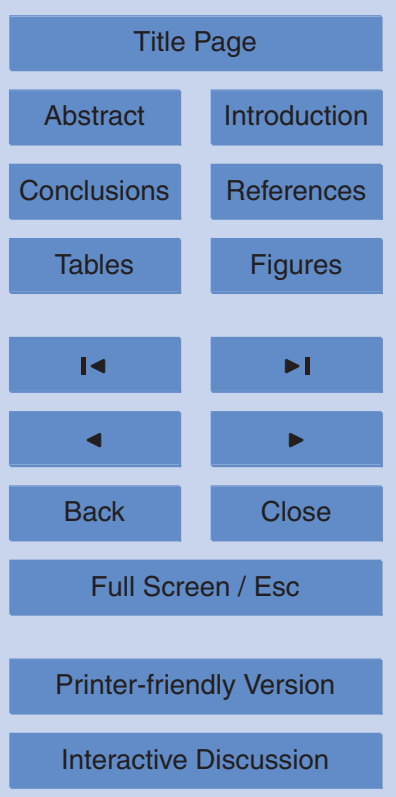

Interactive Discussion 


\section{Retrieval methodology}

In case of spherical albedo and global transmittance measurements, Eqs. (4) and (5) can be used to estimate parameters $x$ and $y$. In particular we derive from Eqs. (4) and (5) (Zege et al., 1980):

$5 \quad x=\operatorname{arsinh}(Q / 2 t)$ and $y=\operatorname{arsinh}(Q / 2 r)$,

where $Q=\sqrt{\left(1+r^{2}-t^{2}\right)^{2}-4 r^{2}}$.

Further $x$ and $y$ can be used to make the retrievals for optical thickness $(\tau)$ for finite layers given by

$\tau=\frac{4 q x}{y}$,

10 where $q=1 /(3(1-g))$. One can assume that $g=0.76$ as for fractal snow grains (Kokhanovsky et al., 2011) and diffuse exponent $(k)$ can be retrieved by substituting the values of $x$ and $\tau$,

$k=x / \tau$.

Extinction coefficient $\left(K_{\text {ext }}\right)$ can be retrieved from optical thickness of finite vertically 15 homogeneous snow with thickness $(H)$ :

$K_{\text {ext }}=\tau / H$.

In the asymptotic region, the light intensity $I(z)$ as a function of depth is explained as asymptotic flux extinction coefficient, which depends on scattering and absorption of light in snow and described as (Domine et al., 2008):

$20 \quad I(z) \propto e^{-\alpha_{0}(\lambda) z}$,

where $\alpha_{0}(\lambda)$ is AFEC and given as (Zege et al., 1991)

$\alpha_{0}(\lambda)=k K_{\text {ext }}$.

Application of asymptotic radiative transfer theory

H. S. Negi et al.

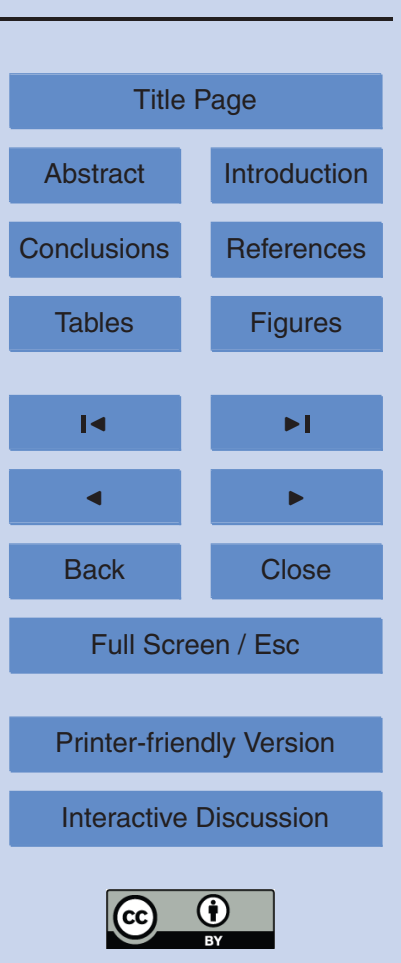


The AFEC can alternatively be derived by the ratio of $x$ to $H$ (geometric thickness) using Eqs. (12) and (13). For an asymptotic region different radiative transfer theories were generated by various authors that can retrieve the AFEC (Bohren and Barkstrom, 1974; Wiscombe and Warren, 1980; Warren 1982; Zege et al., 1991; Hamre et al., 5 2004). Some of them are based on diffusion theory, in which the diffuse attenuation coefficients are parameterized.

Another optical parameter, the probability of photon absorption $\beta$ (i.e. $\left(1-\omega_{0}\right)$ ) can be estimated using Eq. (6), by substituting the value of $g$ :

$\beta=\frac{k^{2}}{N}$.

where $N$ is constant $(=0.72)$ by considering the value of $g$ as 0.76 .

The snow physical parameters i.e. snow density and effective grain size can be retrieved from the snow extinction coefficient $\left(K_{\text {ext }}\right)$ and by knowing one of the snow parameter, as given by following relation (Kokhanovsky and Zege, 2004; Domine et al., 2008):

${ }_{15} K_{\mathrm{ext}}=\frac{3 \rho}{2 \rho_{i} a_{\mathrm{ef}}}$,

where $\rho$ is the density of snow and $\rho_{i}$ is the density of ice $\left(=0.917 \mathrm{~g} \mathrm{~cm}^{-3}\right)$.

The effective grain radius $a_{\text {ef }}$ can also be derived using $\beta$ at NIR channel, given by following relation (Kokhanovsky and Nauss, 2005):

$\beta=\beta_{\infty}(1-\exp (-\alpha \ell))$,

20 where the value of $\beta_{\infty}$ corresponds to the limiting case of an ice crystal, which absorbs all radiation penetrating inside the particle $(\alpha \ell \rightarrow \infty)$. The value of $\beta_{\infty}$ was found 0.47 at $n=1.31$ (for ice) (Kokhanovsky et al., 2011). The particle absorption length (PAL) $\ell$ in Eq. (18) is proportional to $a_{\text {ef }}$ (Kokhanovsky and Nauss, 2005):

$\ell=M a_{\text {ef }}$,

Application of asymptotic radiative transfer theory

H. S. Negi et al.

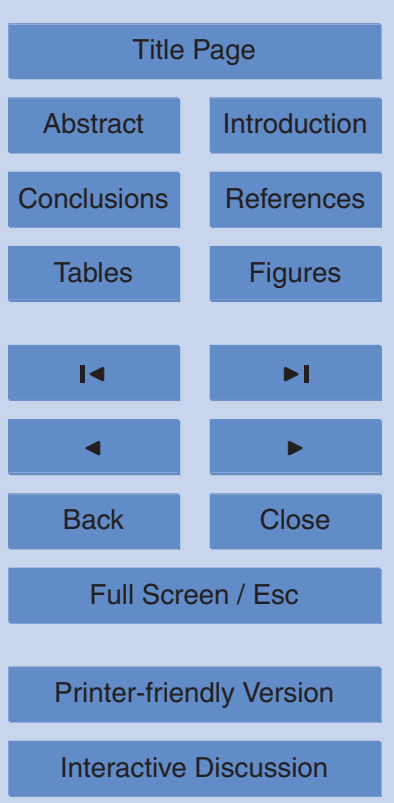


with the parameter $M$ depending on the shape of particles. In this study the value of $M$ was considered as 2.63 for fractals grains (Kokhanovsky et al., 2011). In Eq. (18), $\alpha=\frac{4 \pi \chi}{\lambda}$ is a linear absorption coefficient for ice. The imaginary part of ice refractive index $(\chi)$ was used as tabulated by Warren and Brandt (2008). Thus from Eqs. (18) and (19) $a_{\text {ef }}$ can be estimated as:

$a_{\mathrm{ef}}=(M \alpha)^{-1} \ln \left(\frac{\beta_{\infty}}{\beta_{\infty}-\beta}\right)$.

The "e-folding depth" $\varepsilon(\lambda)$ is the distance through which light propagates in the medium before its intensity is reduced by $1 / \mathrm{e}$ times its initial value in deep snow layers. This parameter can also be retrieved using $\alpha_{0}(\lambda)$ as follows (Domine et al., 2008):

${ }_{10} \varepsilon(\lambda)=\frac{1}{\alpha_{0}(\lambda)}$

In case of reflectance and transmittance measurements, the value of $y$ can be estimated using measured values of reflectance for semi-infinite snow depth. From Eq. (7),

$y=\frac{1}{D\left(\mu, \mu_{0}, \varphi\right)} \ln \left(\frac{R_{\infty}^{0}\left(\mu, \mu_{o}, \varphi\right)}{R_{\infty}\left(\mu, \mu_{o}, \varphi\right)}\right)$.

The values of $y$ can be estimated in visible and NIR region up to $1180 \mathrm{~nm}$, where the reflectance $R_{\infty}\left(\mu, \mu_{o}, \varphi\right)>0.2$, as AART theory only works well for reflectances greater than 20\% (Kokhanovsky, 2006). By substituting $y$ from Eq. (22) and $T$ from Eq. (9), Eq. (8) can be written in terms of $x$ as follows, which can be solved analytically for the parameter $x$ (Appendix):

$R=R_{\infty}^{0} \exp (-y D)-K_{0}(\mu) K_{0}\left(\mu_{0}\right)\left(\frac{e^{y}-e^{-y}}{e^{x+y}-e^{-x-y}}\right) \exp (-y-x)$.

Once the parameters $x$ and $y$ are known from Eqs. (22) and (23), the different snow optical and snow physical parameters can be retrieved using the analytical equations as described from Eqs. (10) to (21).

\section{Application of asymptotic radiative transfer theory}

H. S. Negi et al.

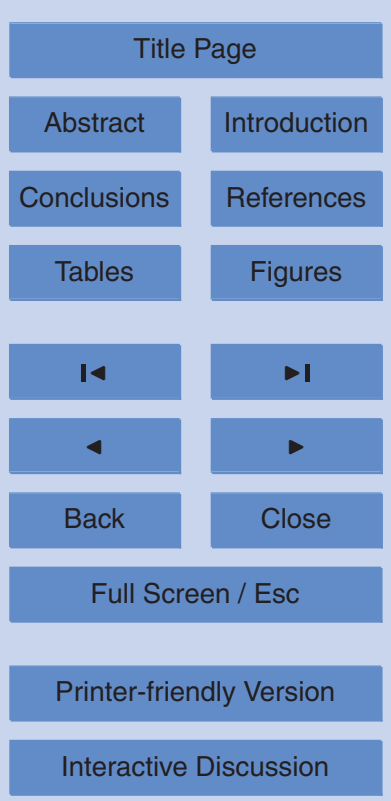




\section{AART theory to experimental data}

\subsection{Measurement description}

Perovich (2007) measured the spectral distribution of light reflected and transmitted from a temperate snow cover. A $2.4 \mathrm{~m} \times 2.4 \mathrm{~m}$ horizontal black painted plywood plat5 form was used for the experiments. Two spectroradiometers were used, one was upward looking placed at the base of the platform to measure the transmitted spectral irradiance and another one for measuring incident and reflected irradiance. Spectral measurements were made between 400 and $1000 \mathrm{~nm}$ wavelength region with $5 \mathrm{~nm}$ spectral resolution. Hemispherical cosine collectors were used for irradiance measurements. The observations were made under cloudy skies with the solar disk either barely visible or not visible. This provides an observational data set of spherical albedo and global transmittance. A series of measurements of incident, reflected and transmitted irradiance were made for different snow depths. Making such observations as the snow depth increases during a storm is difficult due to snowfall during night. Therefore measurements were made with a few centimeters of snow cover incrementally stripped off between each set of measurements. This method also provided measurements on a fairly homogeneous snow cover. Snow physical characteristics, such as snow thickness and density, were measured at the time of optical measurements. Snow grain size and shape were measured using micro photographs and a scale with micro mike (eye piece). The measured snow grain sizes were the maximum equivalent grain diameters (EGD). Snow wetness was measured qualitatively.

In the present study five sets of reflection and transmission data of different types of snow were selected for the comparison with AART retrieved parameters. This includes $19 \mathrm{~cm}$ thick and around one month old snowpack, impact of new snow and impact of snow melt, which provided thick, thin, dry, wet, new and old snow conditions. Per-

ovich (2007) used a "two-stream" radiative transfer model formulation by Dunkle and Bevans (1956). This assumes isotropic scattering and computes the downwelling and upwelling irradiance in a medium. Greenfell and Maykut (1977), Grenfell (1979) and

\section{Application of asymptotic radiative transfer theory}

H. S. Negi et al.

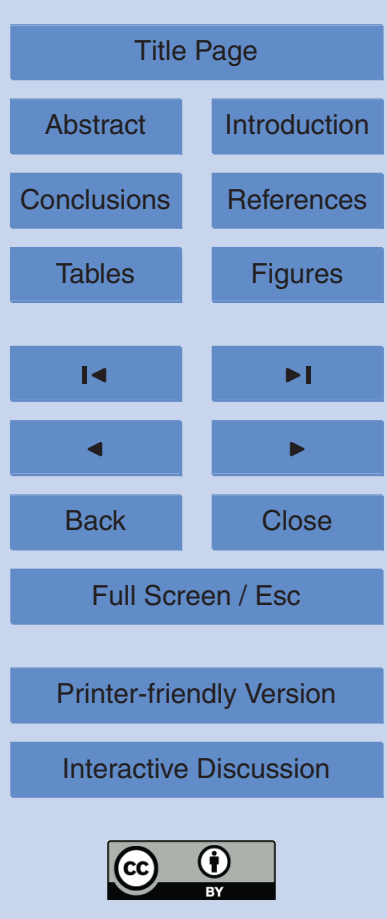




\subsection{Snow optical parameters}

Perovich (2007) analyzed the reflection and transmission snow cover data using a "twostream" radiative transfer model for diffusing medium by Dunkle and Bevans (1956)

5 and estimated the diffuse extinction coefficient also known as asymptotic flux extinction coefficient (AFEC). Figure 1 shows the comparison between AART retrieved AFEC and AFEC derived by Perovich (2007) for a $19 \mathrm{~cm}$ thick snowpack using spherical albedo and global transmittance data. The retrieved AFEC values using AART theory were found to be similar (up to three places of decimal) as derived using the Dunkle and

10 Bevans (1956) model. Figure 2 shows the comparison between AFEC derived by Perovich (2007) and retrieved by AART theory for $14 \mathrm{~cm}$ old snow and $15.5 \mathrm{~cm}$ new snow. In this case similar trends were observed with an average shift of $0.5-0.6 \mathrm{~cm}^{-1}$ in AFEC values. This shift in the AFEC values may be due to presence of $2 \mathrm{~cm}$ crust of frozen aggregated sleet with individual rounded grains of $1-3 \mathrm{~cm}$ in diameter on the 5 top of old snow (Perovich, 2007). Here we feel AART theory does not work correctly for melt freeze crust with large grains. However, the corresponding slight increase in the AFEC due to new snow can be observed using both the theories. Figure 3 shows the spectral dependence of AFEC for dry and wet snow. In this case again a very good agreement was found between AFEC derived by Perovich (2007) and retrieved 20 by AART theory. There is a significant increase in the AFEC values along the entire wavelength region for wet snow. The difference for the high values of AFEC can also be attributed to contamination, as impurities in snow can significantly increase the AFEC in visible region (Choudhury et al., 1981). The presence of particulates and vegetative detritus in wet snow were observed in the field, supporting the increased 25 AFEC for wet snow. The AFEC values observed by different researchers at $450 \mathrm{~nm}$ ranged from 0.07 to $0.17 \mathrm{~cm}^{-1}$ for various types of snow (Choudhury et al., 1981). Using the present theory the AFEC varied from 0.06 to $0.22 \mathrm{~cm}^{-1}$ at $450 \mathrm{~nm}$ for different types of temperate snow. The agreement of AART retrieved AFEC with other theories
$5,1239-1262,2011$

\section{Application of asymptotic radiative transfer theory}

H. S. Negi et al.

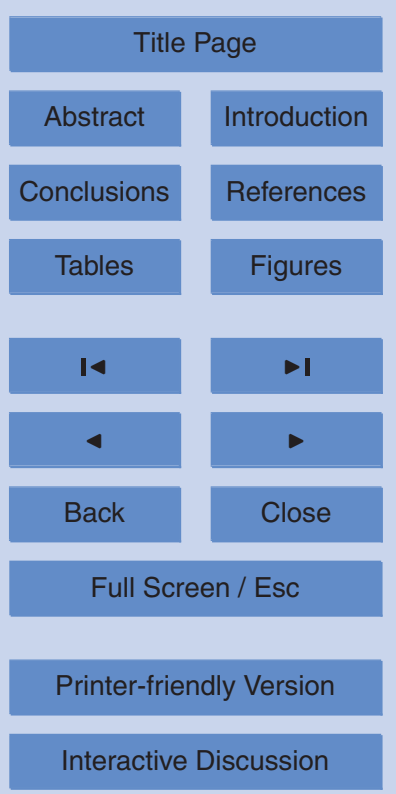


shows that the AART theory can also work well to retrieve snow parameters for different types of snow.

The snow optical thickness (SOT) was estimated using the AART theory from snowpack transmission data. The retrieved SOT shows a linear relation with snow geomet5 ric thickness (Fig. 4). The extinction coefficient $\left(K_{\text {ext }}\right)$ of snow was retrieved using SOT and was roughly $1 \mathrm{~mm}^{-1}$. The extinction coefficients $\left(K_{\text {ext }}\right)$ for different types of snow as discussed above were also retrieved and found to range from 0.5 to $1.0 \mathrm{~mm}^{-1}$.

The probability of photon absorption (PPA) was estimated as a function of wavelength using AART theory. The comparison between PPA of old snow and new snow (only $1.5 \mathrm{~cm}$ new snow on old snow) shows almost similar values for both the snow types in the visible region, but differences at longer wavelengths (Fig. 5a). The old snow has higher PPA, perhaps due to large grain size (Kokhanovsky and Zege, 2004). Similarly, the wet snow PPA was observed to be larger than PPA for dry snow. This may be attributed to larger grain size in wet snow due to clustering of snow grains at the temperature of snow close to its melting point.

The e-folding depths retrieved using AART theory were found in the range between 5 and $25 \mathrm{~cm}$ in the visible region for different types of snow. These values depend on the absorption within the ice, scattering by the snow grains, and reflection at the boundaries of snow layers. The minimum e-folding depth was $5 \mathrm{~cm}$ for wet snow and the maximum was $25 \mathrm{~cm}$ for old dry snow. The e-folding depth was approximately $18 \mathrm{~cm}$ for around one month old $19 \mathrm{~cm}$ thick snow. For $14 \mathrm{~cm}$ old snow and $15.5 \mathrm{~cm}$ snow (with $1.5 \mathrm{~cm}$ new snow on the top of $14 \mathrm{~cm}$ old snow) depths, similar values of e-folding depths 9.8 and 9.2 were observed respectively. Values of e-folding depth retrieved using AART theory are found in the similar range $(5$ to $25 \mathrm{~cm}$ ) as reported by other authors (Domine et al., 2008).

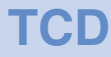

$5,1239-1262,2011$

\section{Application of asymptotic radiative transfer theory}

H. S. Negi et al.

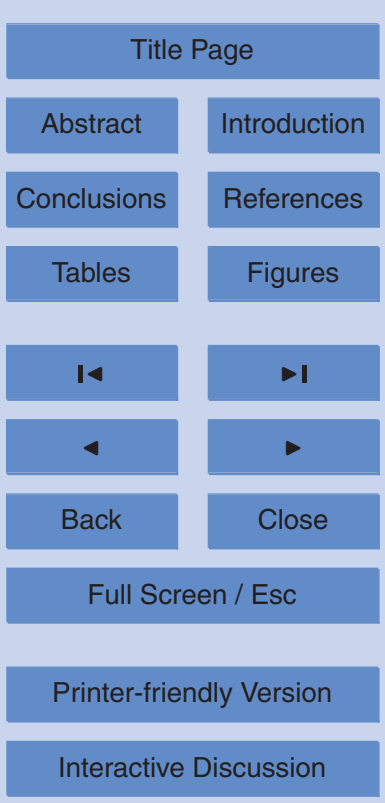




\subsection{Snow grain size and density}

The snow density was retrieved using the estimated extinction coefficient $\left(K_{\text {ext }}\right)$ and measured equivalent grain diameter. It can be observed from Table 1, that the measured snow densities are similar to AART retrieved snow densities, except in case of 5 serial numbers 4 and 5 . The difference for serial no.4 (i.e. dry snow) may be due to the measured grain size being an equivalent snow diameter, which was measured as maximum length of the column snow grains and therefore gives a larger diameter. However, optical sensors measure the effective grain size $\left(a_{\mathrm{ef}}\right)$, which is defined by the average volume and average projection area of a snow grain (Jin et al., 2008; 10 Kokhanovsky, 2011). The measurement of maximum equivalent grain diameter is not a correct measure as reported by Aoki et al. (2000) since the $a_{\text {ef }}$ belongs in the range of measured lengths of narrower portions of broken crystals. However, in case of rounded snow (i.e. spheres), the $a_{\text {ef }}$ is the same as actual radius (Jin et al., 2008; Kokhanovsky et al., 2011). For $11 \mathrm{~cm}$ snow depth (Table 1), the measured grains were rounded and the snow was observed as wet and saturated due to rain. Wet snow normally has a larger density than dry snow (as observed) and generally the large grains formed in wet snow due to clustering (Colbeck, 1982). Therefore the difference in the AART retrieved density may be due to measurement error in the field observation of snow grain size.

Alternatively, the snow grain size can be retrieved using estimated snow $K_{\text {ext }}$ and measured snow density. Table 1 shows that the retrieved snow grains are well in the range of measured snow grain size except for serial number 4 and 5 . For dry snow (14.5 cm thickness), the difference in grain size is due to the retrieved effective diameter and measured maximum equivalent grain diameter as discussed above. For wet snow $(11 \mathrm{~cm})$ the retrieved grain size (around $2 \mathrm{~mm}$ ) observed is larger than measured grain size. This supports the inference of grain size measurement error for wet snow.

5, 1239-1262, 2011

\section{Application of asymptotic radiative transfer theory}

H. S. Negi et al.

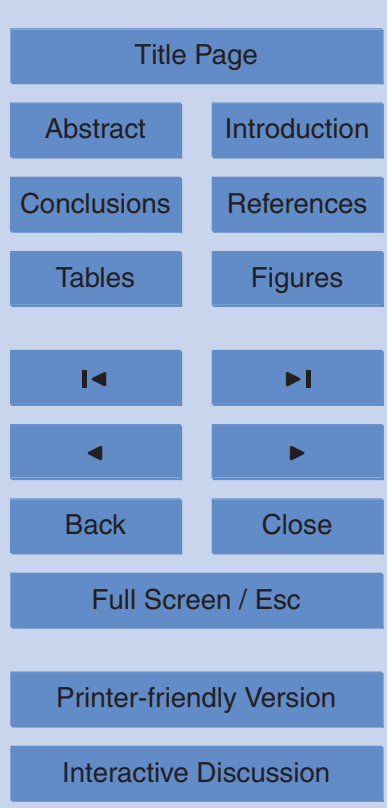


The grain sizes were also retrieved using PPA at $860 \mathrm{~nm}$ and we found similar values as using above method. In this method snow density from the field is not required for retrieving grain size. The advantage of this alternative method is that, using retrieved grain size, snow density can be estimated if we know the snow $K_{\text {ext }}$. Sometime results 5 at $860 \mathrm{~nm}$ may have absorption due to pollution, which can effect the grain size estimation. This could possibly be the reason that the retrieved grain sizes using this method are usually slightly larger than the grain sizes retrieved from the previously discussed method using density (Table 1). Zege et al. (2008) and Kokhanovsky et al. (2011) have modeled the effect of soot in NIR region for retrieving effective grain size from satellite 10 measurements.

\section{Conclusions}

The AART theory has already been applied to many situations such as cloud and atmospheric optics, but this is the first time it has been used to retrieve snow optical and physical properties from reflection and transmission functions of temperate snow cov15 ers. The simple analytical equations using the theory are used to retrieve different snow parameters. Perovich (2007) used the spherical albedo and global transmittance $(r, t)$ measurements to retrieve the AFEC for different types of snow using the theory of Dunkle and Bevans (1956). The similar values of AFEC are found using the AART theory for different types of snow (dry, wet, thin and thick). This shows that AART theory being 20 simpler works as well as the other theory to retrieve AFEC for different types of snow. The only differences in the retrieved AFEC values are found in case of crust of frozen aggregated sleet, where AART theory does not work correctly. In addition with the use of AART theory, snow optical parameters such as $K_{\text {ext }}$, PPA, snow optical thickness, diffuse exponent, e-folding depth are also retrieved. The values of retrieved e-folding

depth are also found in the range between 5 and $25 \mathrm{~cm}$ for different types of snow as reported by others. The analytical equations are also described to retrieve the above parameters using reflectance and transmittance measurements.

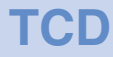

$5,1239-1262,2011$

\section{Application of asymptotic radiative transfer theory}

H. S. Negi et al.

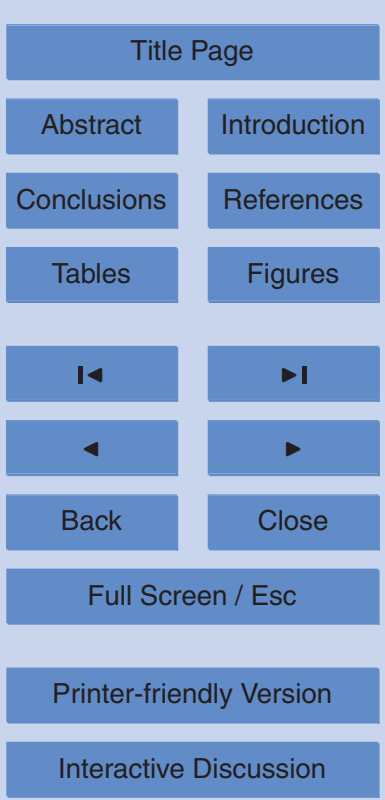


Snow physical parameters such as grain size and density are estimated using retrieved extinction coefficients from reflected and transmitted data and compared with measured values. A difference between measured and retrieved snow density is observed in some cases due to the difference of measured and effective grain diameters.

5 Snow grain sizes are also estimated using PPA at NIR region i.e. $860 \mathrm{~nm}$ and this also supports the results of estimated snow grain size and density from $K_{\text {ext }}$ for different types of snow. This shows that AART theory can work well for different types of snow to estimate snow parameters using simple analytical equations. This method retrieves snow parameters in a computationally fast manner and has importance in many appli-

\section{Appendix A}

Let $e^{x}=Z$,

Eq. (23) can be written as

$\left(R-R_{\infty}^{0} e^{-y D}\right)=K_{0}(\mu) K_{0}\left(\mu_{0}\right)\left(\frac{e^{y}-e^{-y}}{e^{y} \frac{1}{z}-e^{-y} z}\right) e^{-y} z$,

15 Eq. (A2) can be written as

$D=\frac{A z}{\frac{B}{z}-C z}$

where $A=K_{0}(\mu) K_{0}\left(\mu_{0}\right)\left(1-e^{-2 y}\right), B=e^{y}, C=e^{-y}$ and $D=\left(R-R_{\infty}^{0} e^{-y D}\right)$.

$A z^{2}=B D-C D z^{2}$

$z=\sqrt{\frac{B D}{(A+C D)}}$

20 Substituting the value of $z$ in Eq. (A1), value of $x$ can be retrieved. 


\section{Notation}

$R \quad$ reflectance function

$T$ transmittance function

$r$ spherical albedo

$t$ global transmittance

$\mu \quad$ solar zenith angle

$\mu_{0} \quad$ viewing zenith angle

$\varphi \quad$ relative azimuth angle

$\omega_{0} \quad$ single scattering albedo

$g$ asymmetry parameter

$\theta \quad$ scattering angle

$p(\theta)$ phase function

$K_{0} \quad$ escape function

$k \quad$ diffuse exponent

$\beta \quad$ probability of photon absorption (PPA)

$\alpha_{0} \quad$ asymptotic flux extinction coefficient (AFEC)

$\ell \quad$ particle absorption length (PAL)

$a_{\text {ef }} \quad$ effective radius

$\rho$ density of snow

$\rho_{i} \quad$ density of ice

$\chi \quad$ imaginary part of the ice refractive index

$\varepsilon \quad$ e-folding depth

$\lambda \quad$ wavelength of light

$\alpha \quad$ linear absorption coefficient for ice

$\tau \quad$ optical thickness

$K_{\text {ext }}$ extinction coefficient

\section{Application of asymptotic radiative transfer theory}

H. S. Negi et al.

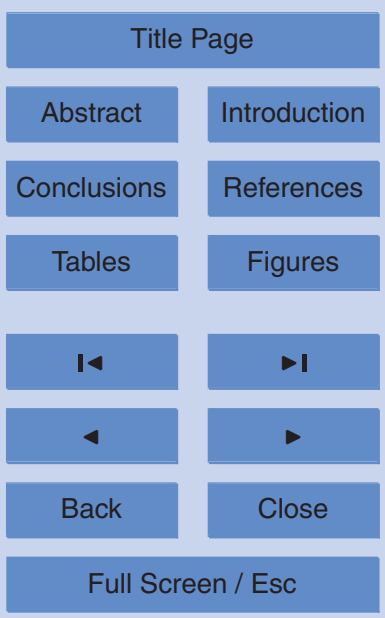

Printer-friendly Version

Interactive Discussion 
Acknowledgements. The authors are thankful to Snow \& Avalanche Study Establishment (SASE), DRDO, India and IUP, University of Bremen, Germany to encourage and support this study. The authors are grateful to A. Ganju, SASE, India and J. B. Burrows, IUP, University of Bremen, Germany, for kind support. A. Kokhanovsky thanks ESA (Snow-Radiance Project), 5 JAXA (SGLI Cryosphere Project) and the BMBF Project CLIMSLIP for support of this research.

\section{References}

Aoki, T., Aoki, T., Fukabori, M., Hachikubo, A., Tachibana, Y. and Nishio, F.: Effects of snow physical parameters on spectral albedo and bi-directional reflectance of snow surface, J. Geophys. Res., 105(D8), 10219-10236, 2000.

Bohren, C. F. and Barkstrom, B. R.: Theory of the optical properties of snow, J. Geophys. Res., 79(30), 4527-4535, 1974.

Chandrasekhar, S.: Radiative Transfer, Oxford University Press, Oxford, 1950.

Choudhury, B. J., Mo, T., Wang, J. R. and Chang, A. T. C.: Albedo and flux extinction coefficients of impure snow for diffuse short-wave radiation, Cold Regions Science and Technology, 5(2), 15 119-125, 1981.

Colbeck, S. C.: An overview of seasonal snow metamorphism, Rev. Geophys. and Space Phys., 20, 45-61, 1982.

Domine, F., Albert, M., Huthwelker, T., Jacobi, H.-W., Kokhanovsky, A. A., Lehning, M., Picard, G., and Simpson, W. R.: Snow physics as relevant to snow photochemistry, Atmos. Chem. Phys., 8, 171-208, doi:10.5194/acp-8-171-2008, 2008.

Dunkle, R. V. and Bevans, J. T.: An approximate analysis of the solar reflectance and transmittance of a snow cover. J. Meteorology, 13(2), 212-216, 1956.

Grenfell, T. C.: The effects of ice thickness on the exchange of solar radiation over the polar oceans, J. Glaciol., 22(87), 305-320, 1979.

25 Grenfell, T. C. and Maykut, G. A.: The optical properties of ice and snow in the Arctic basin, J. Glaciol., 18, 445-463, 1977.

Hamre, B., Winther, J. G., Gerland, S., Stamnes J. J., and Stamnes, K.: Modeled and measured optical transmittance of snowcovered first-year sea ice in Kongsfjorden, Svalbard, J. Geophys. Res., 1109, C10006, doi:10.1029/2003JC001926, 2004.

Jin, Z., Charlock, T. P., Yang, P., Xie, Y., and Miller, W.: Snow optical properties for different

\section{Application of asymptotic radiative transfer theory}

H. S. Negi et al.

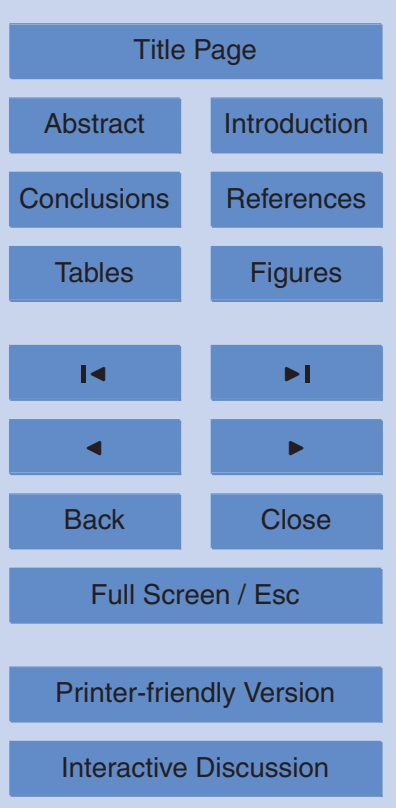


particle shapes with application to snow grain size retrieval and MODIS/CERES radiance comparison over Antarctica, Remote Sens. Environ., 112, 3563-3581, 2008.

Kokhanovsky, A. A.: Polarization optics of random media, Springer, Dordrecht, UK, 2003.

Kokhanovsky, A. A.: Cloud optics, Springer-Praxis, Chichester, The Netherlands, 2006.

5 Kokhanovsky, A. A. and Nauss, T.: Satellite based retrieval of ice cloud properties using semianalytical algorithm, J. Geophys. Res., D110(D19206), doi:10.1029/2004JD005744, 2005.

Kokhanovsky, A. A. and Zege, E. P.: Scattering optics of snow, Appl. Optics, 43, 1589-1602, 2004.

Kokhanovsky, A. A., Rozanov, V. V., Aoki, T., Odermatt, D., Brockmann, B., Kruger, O., Bouvet, M., Drusch, M., and Hori, M.: Sizing snow grains using backscattered solar light, Int. J. Remote Sens., in press, 2011.

Liou, K. N.: An Introduction to Atmospheric Radiation, Academic Press, New York, USA, 2002.

Minin, I. N.: Radiative Transfer Theory in Planetary Atmospheres, Nauka, Moscow, Russia, 1988.

Mishchenko, M. I., Travis, L. D., and Lacis, A. A.: Scattering, absorption, and emission of light by small particles, Cambridge U. Press, Cambridge, 2002.

Nakajima, T., and M. Tanaka: Algorithms for radiative intensity calculations in moderately thick atmospheres using a truncation approximation, J. Quant. Spectr. Radiative Transfer, 40, 5169, 1988.

20

Perovich, D. K.: Theoretical aspects of light reflection and transmission by spatially complex and temporally varying sea ice covers, J. Geophys. Res., 95(C6), 9557-9567, 1990.

Perovich, D. K.: Light reflection and transmission by a temperate snow cover, J. Glacio., 53, 201-210, 2007.

Rozenberg, G. V.: Physical foundations of light scattering media spectroscopy, Sov. Phys. Uspekhi, 91, 569-608, 1967.

Siewert, C. E.: A discrete-ordinates solution for radiative-transfer models that include polarization effects, J. Quant. Spectr. Rad. Transfer, 64, 227-254, 2000.

Sobolev, V. V.: Light Scattering in Planetary Atmospheres, Pergamon Press, New York, USA, 1975.

30 Thomas, G. and Stamnes, K.: Radiative Transfer in the Atmosphere and Ocean, Cambridge University Press, Cambridge, 1999.

Van de Hulst, H. C.: Multiple Light Scattering: Tables, Formulas and Applications, Academic Press, New York, USA, 1980.
5, 1239-1262, 2011

\section{Application of \\ asymptotic radiative transfer theory}

H. S. Negi et al.

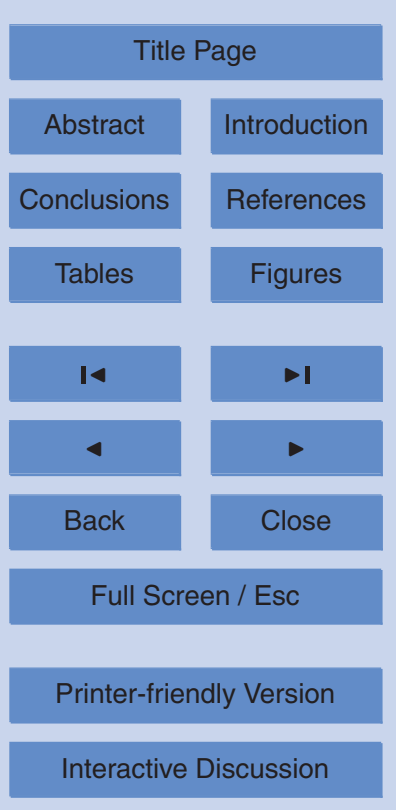

Interactive Discussion 
Warren, S. G.: Optical Properties of Snow. Rev. Geophys. Space Phys., 20(1), 67-89, 1982.

Warren, S. G. and Brandt, R. E.: Optical constant of ice from the ultraviolet to the microwave: A revised compilation, J. Geophy. Res., 113, D114220, doi:10.1029/2007JD009744, 2008.

Wiscombe, W. J. and Warren, S. G.: A model for the spectral albedo of snow-I: pure snow, J. Atmos. Sci., 37, 2712-2733, 1980.

Yanovitskij, E. G.: Light Scattering in Inhomogeneous Atmospheres, Springer-Verlag, New York, USA, 1997.

Zege, E. P., Znachenok, M. P., and Katsev I. L.: Determination of the optical characteristics of scattering layers from diffuse reflection and transmission, Zhurnal Prikladnoi Spektroskopii, 33(3), 735-741, 1980.

Zege, E. P., Ivanov, A. P., and Katsev, I. L.: Image transfer through a scattering medium, Springer-Verlag, New York, USA, 1991.

Zege, E., Katsev, I., Malinka, A., Prikhach, A., and Polonsky, I.: New algorithm to retrieve the effective snow grain size and pollution amount from satellite data, Ann. Glaciol., 49, 139-144, 2008.

\section{Application of asymptotic radiative transfer theory}

H. S. Negi et al.

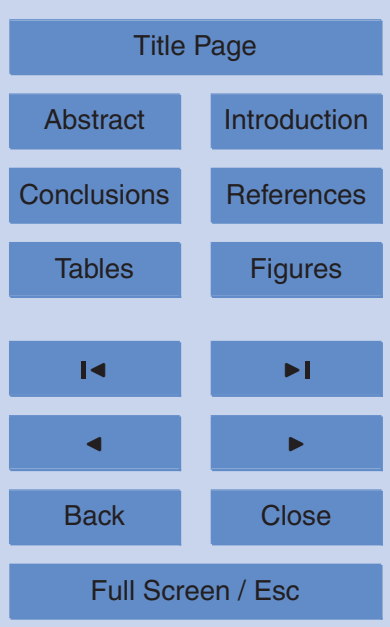

Printer-friendly Version

Interactive Discussion 
Table 1. AART retrieved snow parameters using derived extinction coefficient $\left(K_{\text {ext }}\right)$ and measured snow parameters.

\begin{tabular}{|c|c|c|c|c|c|c|c|}
\hline \multirow[t]{2}{*}{ S. No. } & \multirow[t]{2}{*}{$\begin{array}{l}\text { Figure reference } \\
\text { (snow depth) }\end{array}$} & \multirow{2}{*}{$\begin{array}{r}\text { Measured snow } \\
\text { density } \\
\left(\mathrm{kg} \mathrm{m}^{-3}\right)\end{array}$} & \multirow{2}{*}{$\begin{array}{l}\text { Measured snow } \\
\text { grain diameter } \\
(\mathrm{mm}) \text { and shape }\end{array}$} & \multirow{2}{*}{$\begin{array}{r}\text { Derived } \\
K_{\text {ext }} \\
\left(\mathrm{mm}^{-1}\right)\end{array}$} & \multirow{2}{*}{$\begin{array}{r}\text { Retrieved snow density } \\
\text { using measured } \\
\text { grain size } \\
\left(\mathrm{kg} \mathrm{m}^{-3}\right)\end{array}$} & \multicolumn{2}{|c|}{$\begin{array}{l}\text { Retrieved snow grain } \\
\text { diameter }(\mathrm{mm})\end{array}$} \\
\hline & & & & & & using density & $\begin{array}{l}\text { using PPA } \\
\text { at } 860 \mathrm{~mm}\end{array}$ \\
\hline (1) & $\begin{array}{r}\text { Fig. } 1 \\
(19.0 \mathrm{~cm})\end{array}$ & 120 & $\begin{array}{r}0.25-0.5 \\
\text { (Round) }\end{array}$ & 0.92 & $68-137$ & 0.33 & 0.42 \\
\hline (2) & $\begin{array}{r}\text { Fig. } 2 \\
(14.0 \mathrm{~cm})\end{array}$ & 200 & $\begin{array}{l}0.5-1.0 \\
\text { (Round) }\end{array}$ & 0.63 & $96-193$ & 1.03 & 1.4 \\
\hline (3) & $\begin{array}{r}\text { Fig. } 2 \\
(15.5 \mathrm{~cm})\end{array}$ & 172 & $\begin{array}{r}0.5-1.0 \\
\text { (Round) }\end{array}$ & 0.68 & $104-208$ & 0.83 & 0.84 \\
\hline (4) & $\begin{array}{r}\text { Fig. } 3 \\
(14.5 \mathrm{~cm})\end{array}$ & 143 & $\begin{array}{r}1.0-3.0 \\
\text { (Column) }\end{array}$ & 0.70 & $215-647$ & 0.67 & 0.62 \\
\hline (5) & $\begin{array}{r}\text { Fig. } 3 \\
(11.0 \mathrm{~cm})\end{array}$ & 373 & $\begin{array}{l}0.5-1.0 \\
\text { (Round) }\end{array}$ & 0.55 & $92-183$ & 2.22 & 3.25 \\
\hline
\end{tabular}

\section{Application of asymptotic radiative transfer theory}

H. S. Negi et al.

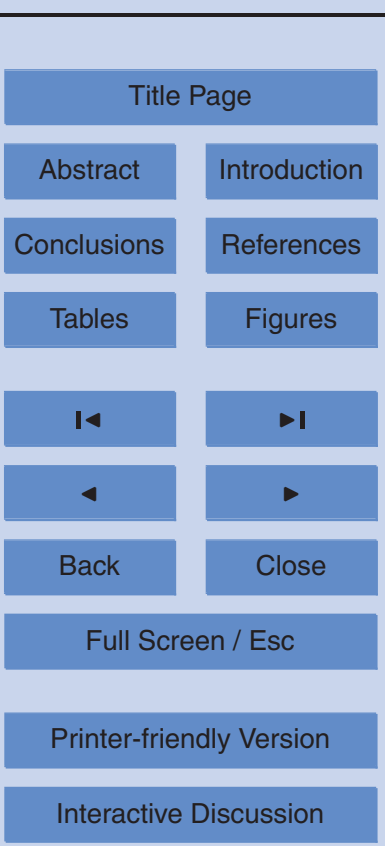




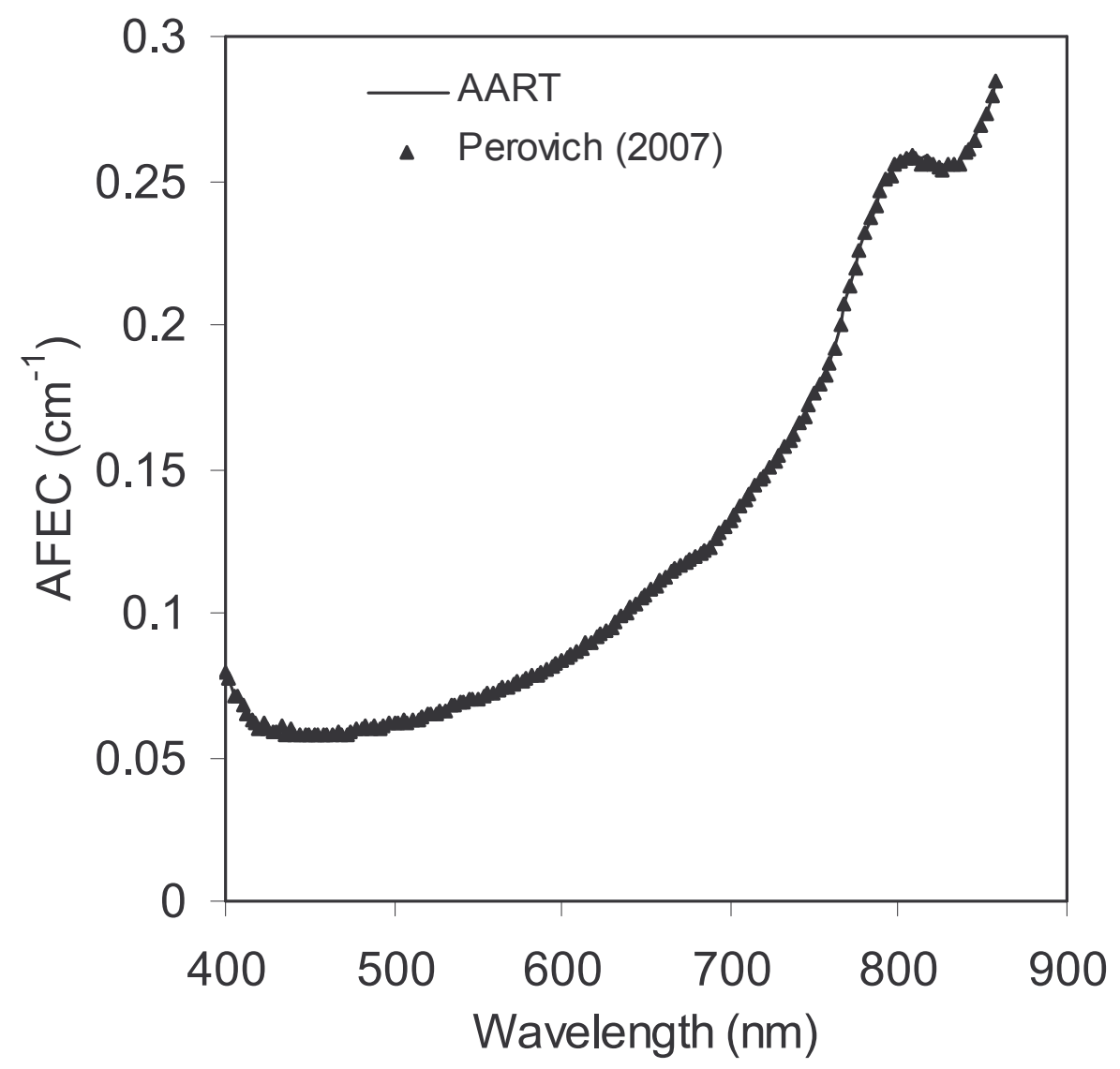

Fig. 1. The comparison between AART retrieved AFEC and AFEC derived by Perovich (2007) for $19 \mathrm{~cm}$ deep snow, on 4 March 1994 snowpack.
TCD

$5,1239-1262,2011$

Application of asymptotic radiative transfer theory

H. S. Negi et al.

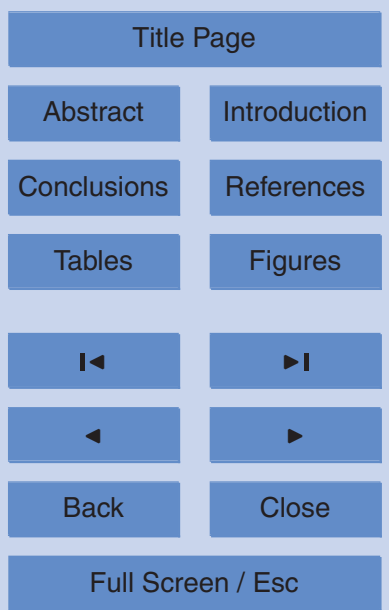

Printer-friendly Version

Interactive Discussion 


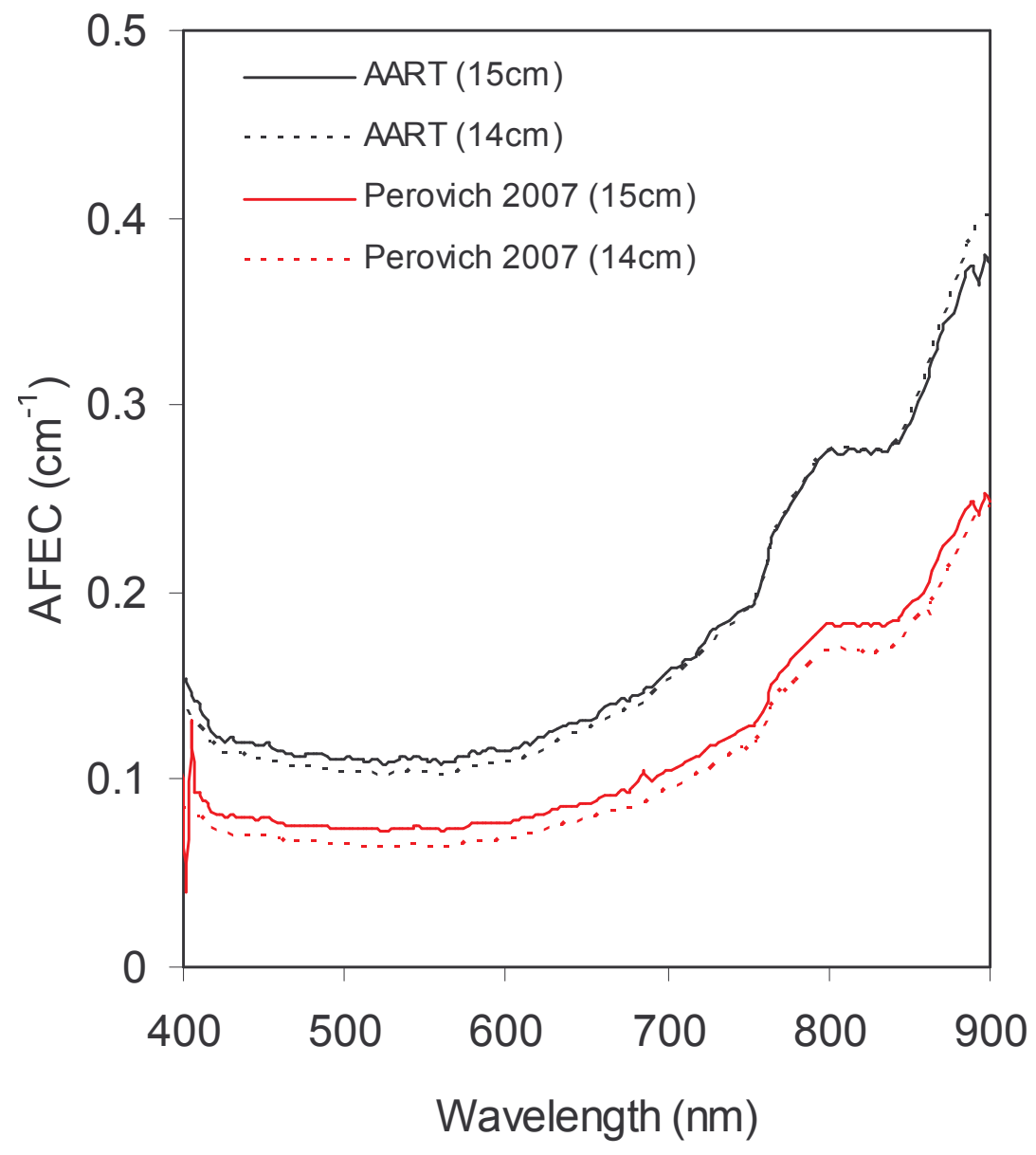

Fig. 2. The comparison between AART retrieved AFEC and AFEC derived by Perovich (2007) for old and new snow on 12 February 1997 snowpack.

\section{TCD}

5, 1239-1262, 2011

Application of asymptotic radiative transfer theory

H. S. Negi et al.

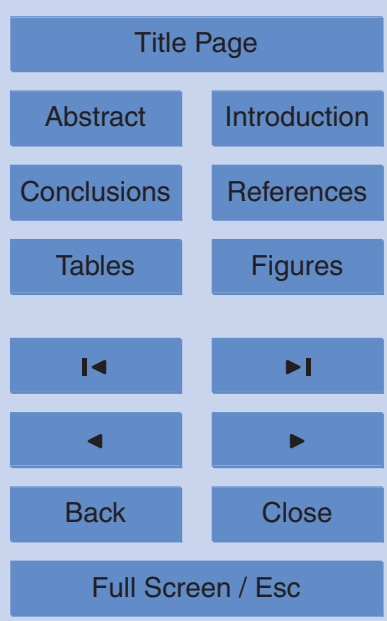

Printer-friendly Version

Interactive Discussion

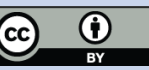




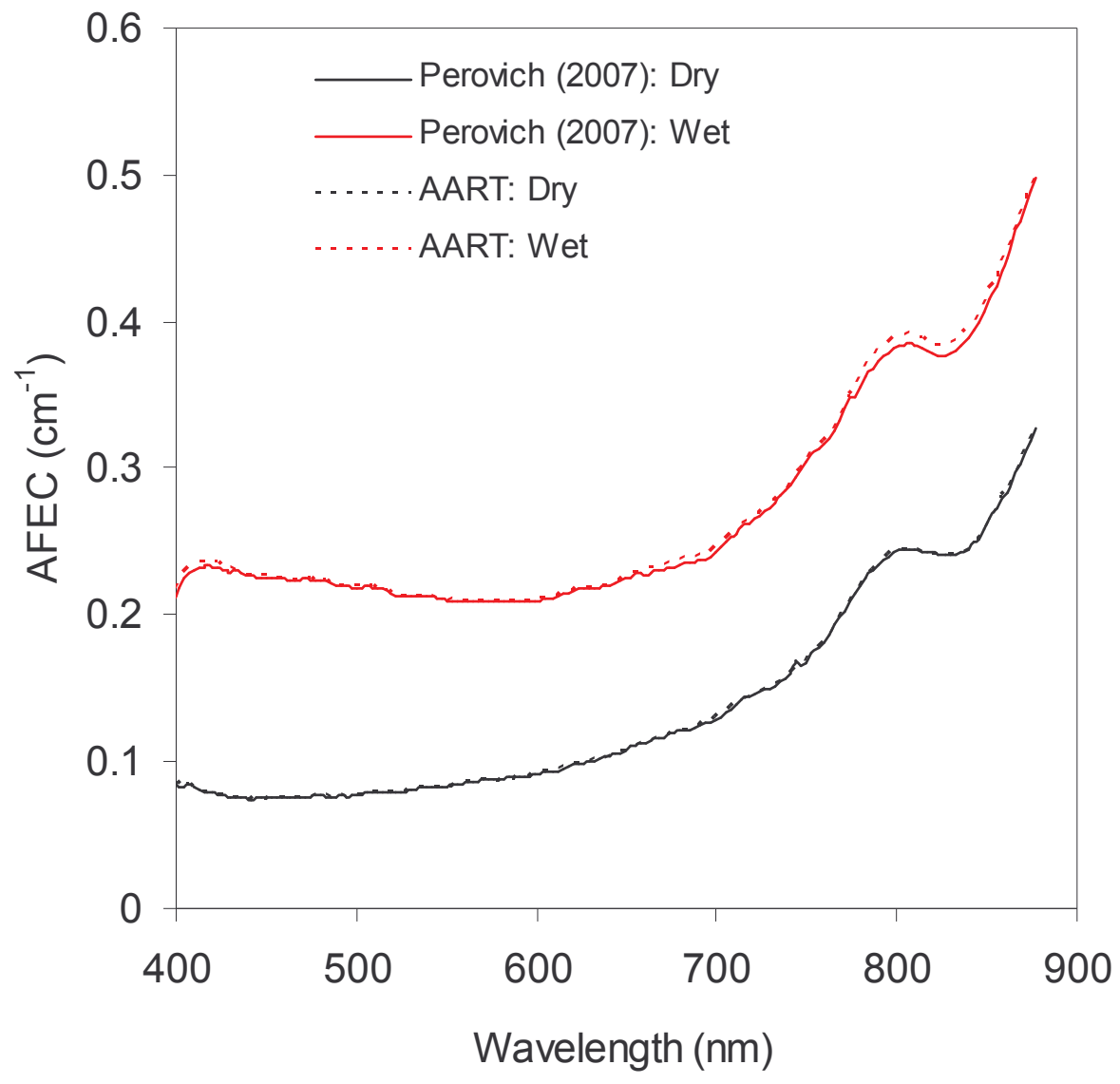

Fig. 3. The comparison between AART retrieved AFEC and AFEC derived by Perovich (2007) for dry and wet snow (dry snowpack: 12 January 1996 and wet snowpack: 18 January 1996).
TCD

$5,1239-1262,2011$

Application of asymptotic radiative transfer theory

H. S. Negi et al.

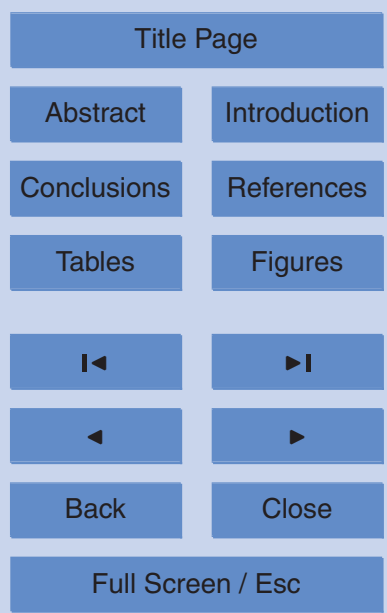

Printer-friendly Version

Interactive Discussion 


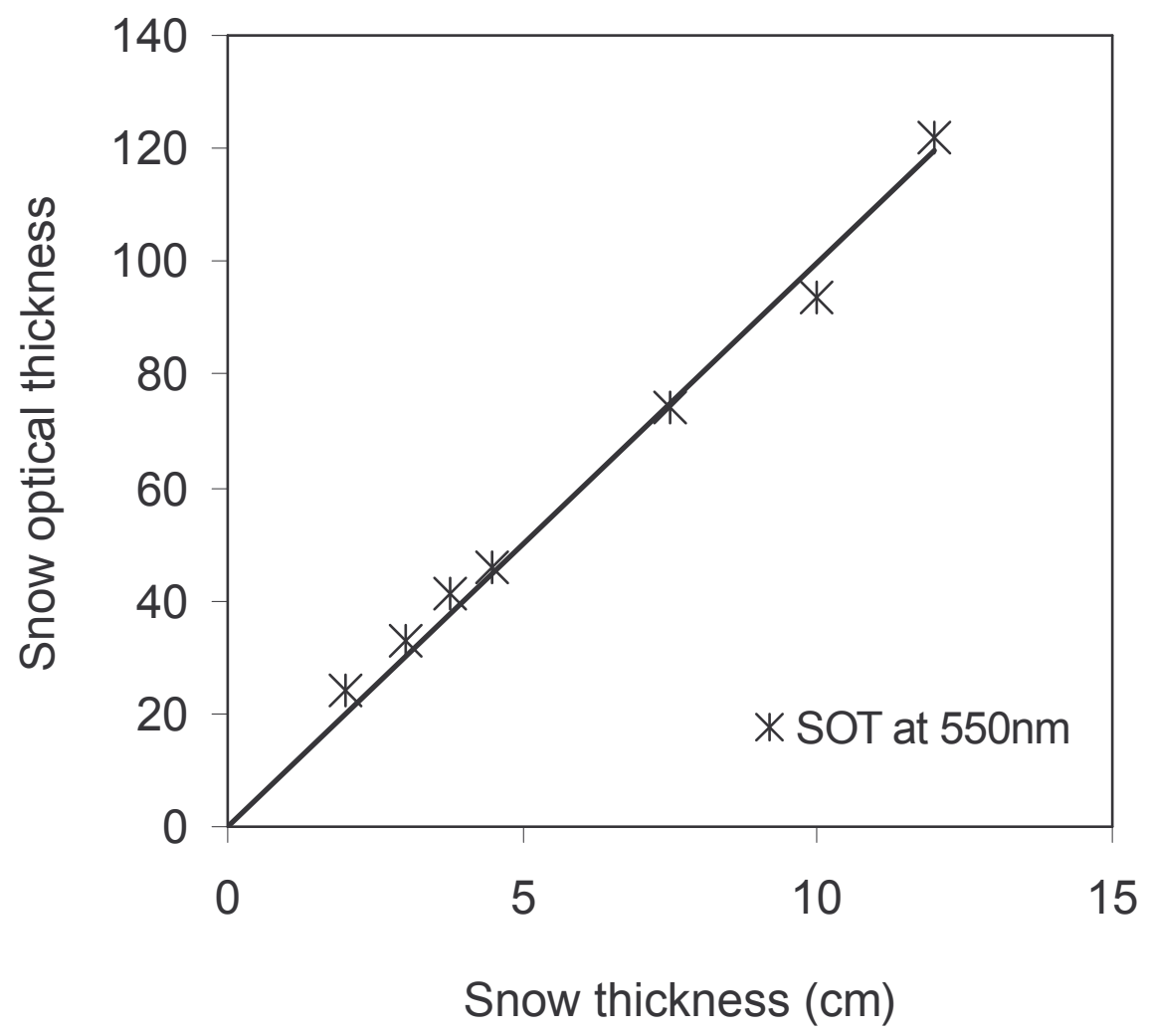

TCD

$5,1239-1262,2011$

Application of asymptotic radiative transfer theory

H. S. Negi et al.

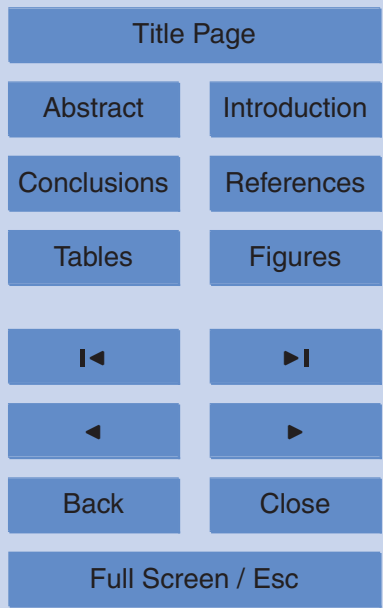

Fig. 4. The ratio of AART retrieved snow optical thickness (SOT) to snow geometric thickness $(\mathrm{H})$.

Printer-friendly Version

Interactive Discussion 


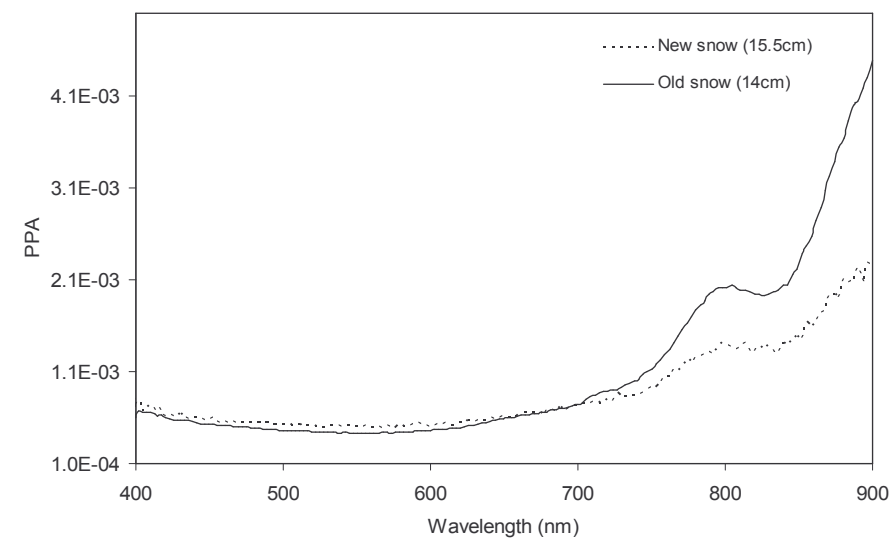

TCD

$5,1239-1262,2011$

\section{Application of asymptotic radiative transfer theory}

H. S. Negi et al.

(a)

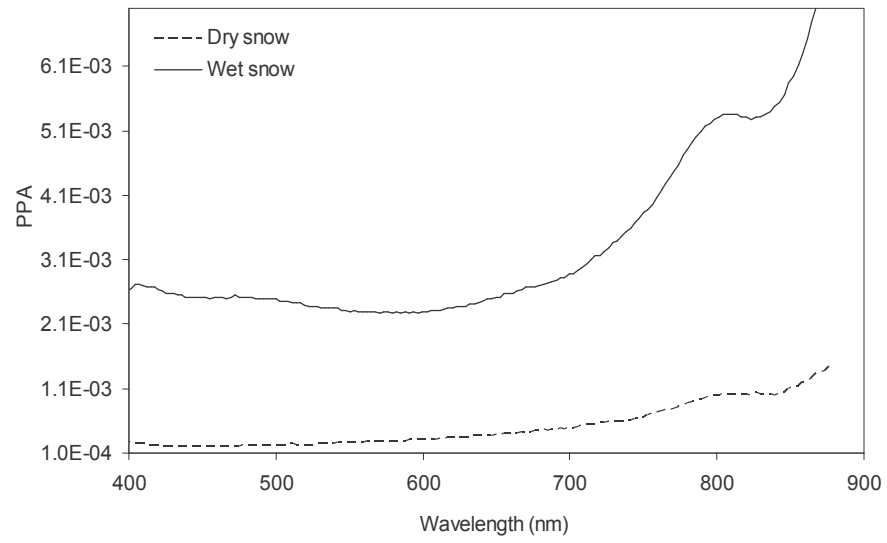

(b)

Fig. 5. The probability of photon absorption (PPA) retrieved using AART theory for (a) old and new snow, (b) dry and wet snow.

Title Page

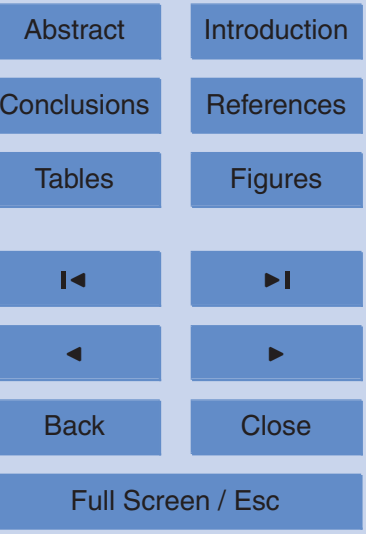

Printer-friendly Version

Interactive Discussion 